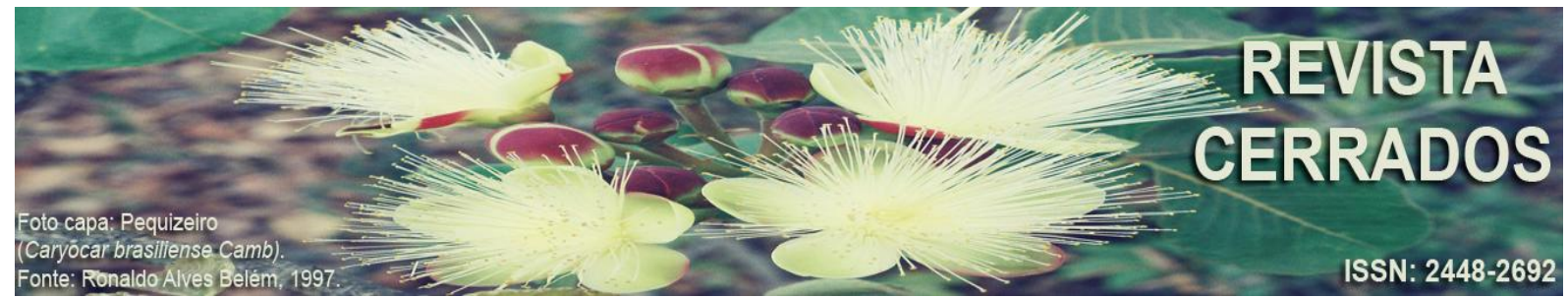

\title{
ASPECTOS DE PRECARIEDADE URBANA NOS BAIRROS ITABERABA E JOÃO PAULO II EM JUAZEIRO (BA)
}

\author{
ASPECTS ABOUT THE URBAN PRECARITY ON THE \\ NEIGHBORHOODS OF ITABERABA AND JOAO PAULO II IN \\ JUAZEIRO (BA)
}

\section{ASPECTOS DE PRECARIEDAD URBANA EN LOS BAIRROS ITABERABA Y JOAO PAULO II EN JUAZEIRO (BA)}

\author{
Cícero Harisson Souza \\ Universidade Federal de Pernambuco - UFPE \\ E-mail: 〈harisson.feeling@gmail.com>. \\ Luciana Duccini \\ Universidade Federal do Vale do São Francisco - UNIVASF \\ E-mail: <luduccini@gmail.com>.
}

\begin{abstract}
Resumo
Os bairros João Paulo II e Itaberaba estão situados na região sul da área urbana de Juazeiro da Bahia, no Brasil. O perfil de seus residentes consiste em pessoas de renda média baixa, migrantes de outros municípios, com uma vasta lista de reivindicações sociais por melhorias na qualidade de vida. Em 2014, o projeto de extensão Construindo o Direto à Cidade a partir do Bairro, desenvolvido por pesquisadores da Universidade Federal do Vale do São Francisco, tinha como objetivo construir formas contextualizadas localmente de atuar contra processos que restringem o direito à cidade por parcelas da população de Juazeiro. A partir da compreensão de que o uso social do espaço costuma relegar populações de menor renda às areas com maiores precariedades estruturais de urbanização, o projeto buscou compreender a apropriação subjetiva do espaço dos bairros como base teórica para a intervenção. Este trabalho é uma síntese dos resultados encontrados e promove um comparativo entre as áreas de atuação.
\end{abstract}

Palavras-chave: Desigualdade Socioespacial; Cidades Médias; Urbanização; Direito a Cidade. 


\begin{abstract}
The neighborhoods of Joao Paulo II and Itaberaba are located in the southern part of the urban area of Juazeiro da Bahia, Brazil. The its residents' profile consists of low mean income people, migrants from other municipalities, with a large list of social demands for improvements in quality of life. In 2014, the project, "Building up the Right to the City from the Neighborhood", developed by researchers of the Federal University of the São Francisco Valley, it aimed to construct locally contextualized forms of action against processes that restrict the right to the city by a fraction of the population of Juazeiro. Understanding that the social use of space usually relegates lower income populations to areas with greater structural precariousness in urbanization, the project sought to understand the subjective appropriation of the neighborhood's space as a theoretical basis for intervention. This work is a synthesis of the results found and promotes a comparison between the areas of performance.
\end{abstract}

Key words: Socio-spatial Inequality; Medium Cities; Urbanization; Right to the City.

\title{
Resumen
}

Los barrios João Paulo II e Itaberaba están situados en la región sur del área urbana de Juazeiro da Bahia, Brasil. El perfil de sus residentes consiste de personas de renta media baja, migrantes de otros municipios, con una vasta lista de reivindicaciones sociales por mejoras en la calidad de vida. En 2014, el proyecto de extensión Construyendo el Directo a la Ciudad a partir del Barrio, desarrollado por investigadores de la Universidad Federal del Valle del São Francisco, tenía como objetivo construir formas contextualizadas localmente de actuar contra procesos que restringen el derecho a la ciudad por parcelas de la población de Juazeiro. A partir de la comprensión de que el uso social del espacio suele relegar poblaciones de menor renta a las áreas con mayores precariedades estructurales de urbanización, el proyecto buscó comprender la apropiación subjetiva del espacio de los barrios como base teórica para la intervención. Este trabajo es una síntesis de los resultados encontrados y promueve un comparativo entre las áreas de actuación.

Palabras clave: Desigualdad Socioespacial; Ciudades Medias; Urbanización; Derecho a la Ciudad.

\section{INTRODUÇÃO}

A história dos bairros João Paulo II e Itaberaba está intimamente ligada às formas de ocupação urbana sanfranciscana. Entre as décadas de 1980 e 1990, a cidade baiana obteve um expressivo crescimento de sua população urbana. De acordo com o IBGE, em 1980 eram 64.233 habitantes na área urbana. Na década seguinte este número passou para 102.266 residentes, denotando um aumento percentual da taxa de urbanização de $54 \%$ para 
79\% neste período. O censo demográfico mais recente, em 2010, contabilizou 160.775 habitantes, representando $81 \%$ da população do município.

Estes bairros periféricos surgiram entre as décadas de 1980 e 1990, e abrigaram parte da população vulnerável a precariedade urbana. A disponibilidade de terrenos em baixo custo foi um dos fatores de atração dessa parcela da população, justamente por não dispor de elementos que caracterizassem valorização imobiliária - pavimentação, saneamento básico, entre outros.

\section{Figura 1 - Localização dos bairros João Paulo II e Itaberaba em Juazeiro}

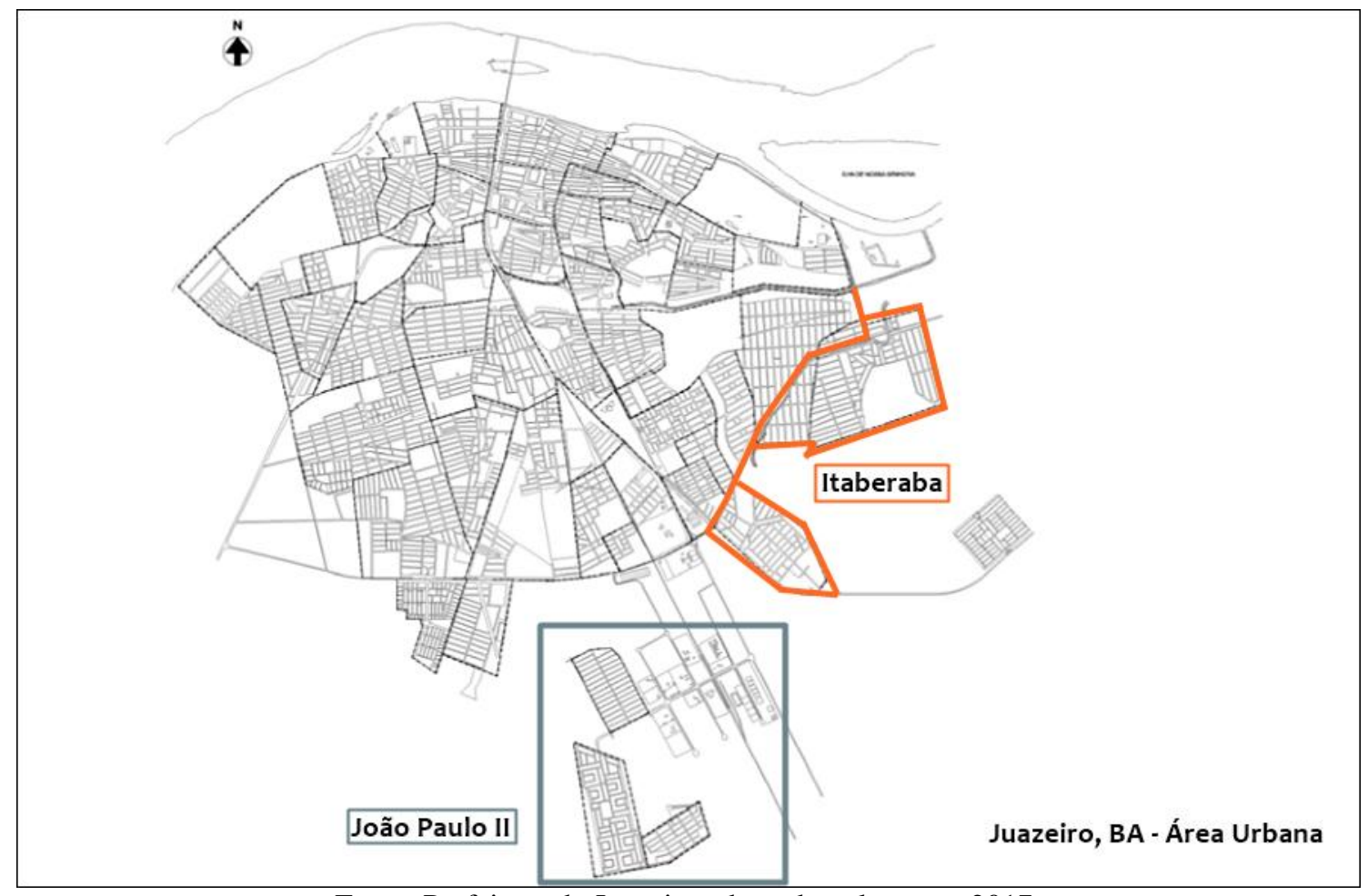

Fonte: Prefeitura de Juazeiro adaptado pelo autor, 2017.

O projeto de extensão, implementado pela Universidade Federal do Vale do São Francisco e intitulado: "Direto à Cidade a partir do Bairro" realizado no ano de 2014, diagnosticou alguns aspectos interessantes em sua abordagem, revelando semelhanças e diferenças entre os bairros de Itaberaba e do João Paulo II. O objetivo do projeto foi de construir formas contextualizadas localmente de atuar contra processos que restringem o direito à cidade por parcelas da população de Juazeiro.

Segundo Ermínia Maricato (2013), a cidade pode ser pensada, ao mesmo tempo, como solo em que se reproduz a força de trabalho (e onde nem todas comodidades da vida urbana podem ser adquiridas através de renda privada), como produto ou negócio (que 
envolve produção, juros e rendas) e como um grande patrimônio sendo que, neste último ponto, no Brasil, há uma histórica apropriação desigual desse patrimônio por diferentes parcelas da população em função de suas rendas e dos diferentes pontos da malha urbana em que se localizam os espaços que lhes são acessíveis.

Contudo, a Maricato (2013) salienta que há também uma lógica que rege as relações entre esses pontos de vista e envolve, ainda, a alocação de recursos públicos em diferentes áreas. Assim, as discrepâncias observáveis no acesso aos serviços coletivos em bairros diversos, não podem ser remetidas, automaticamente, à distância em que se encontram das áreas centrais.

A perspectiva conhecida como teoria das localidades centrais, sustenta que o valor da terra urbana é determinado pela distância a que esta se encontra com relação aos centros mais antigos (e já providos de variedade de atividades, serviços e infraestrutura) da cidade (GOTTDIENER, 2010). Dessa forma, novas atividades e ocupações seriam distribuídas pelo espaço da cidade em função dos custos-benefícios particulares (a depender de necessidades de matéria-prima, transporte, mão de obra, ou outros elementos econômicos) e poderíamos dizer que o padrão de ocupação espacial de uma área urbana seria decorrente de aspectos técnicos racionalmente considerados. Segundo esta lógica, bairros mais afastados apresentariam menor valor imobiliário devido ao distanciamento das áreas centrais com ocupação mais antiga o que, por sua vez, determinaria maior dificuldade técnica e menor interesse na oferta de serviços coletivos.

As ocupações mais distantes seriam, então, menos providas e menos valorizadas do que as mais antigas, em particular pelas necessidades de transporte. A tendência atual de construção de condomínios residenciais fechados para as classes médias e altas em áreas, ainda na década de 1980 reconhecidos por Caldeira (1997) de "enclaves fortificados" estaria, desta forma, na contramão da teoria das localidades centrais, uma vez que ergue áreas completamente dotadas de infraestrutura e serviços (incluindo os de lazer) em locais distantes e, muitas vezes, desabitados.

Segundo Gottdiener (2010), esta forma de análise apresenta vários problemas, a começar pela utilização de um conceito de centralidade ultrapassado (GOTTDIENER, 2010, p. 52) e, mais grave, por sua tendência mecanicista de compreensão dos diferentes valores das áreas urbanas, decorrente de considerar a tecnologia como "agente principal de mudança na sociedade", ignorando a existência do conflito entre os diversos agentes sociais 
(GOTTDIENER, 2010, p. 54). O conceito anterior de centralidade fazia referência à concentração em um ponto central de construções e ocupações mais antigas, a partir das quais a cidade cresceria como um "organismo natural", expandindo-se pelos arredores segundo seu crescimento demográfico e econômico. O centro, por ser o ponto original de ocupação, seria então a referência básica para a valorização das áreas posteriormente ocupadas. Hoje, muitos autores questionam esta noção a partir de observações teóricas e empíricas (os "enclaves fortificados", o surgimento de "novas centralidades" e as "cidades policêntricas").

O surgimento de "novas centralidades", conforme crescem as cidades atualmente, não contradiz a relevância do conceito, ao contrário, fez ressurgir o cerne da questão, que Henri Lefebvre já havia destacado: trata-se de uma dinâmica e de uma lógica de construção do espaço por grupos sociais. Para Lefebvre (1999), centralidade é um conceito fundamental na própria definição do urbano, mas não como ponto geométrico e sim como tendência centrípeta com relação a diversas funções, atividades e grupos sociais variados:

\footnotetext{
Não existe cidade, nem realidade urbana sem um centro. Mais que isso: o espaço urbano se define, já dissemos, pelo vetor nulo; é um espaço onde cada ponto, virtualmente, pode atrair para si tudo o que povoa as imediações: coisas, obras, pessoas. [...] Por conseguinte, não se pode deixar de defender a concentração urbana, com seus riscos de saturação, de desordem, e suas oportunidades de encontros, de informações, de convergências. [...] O centro só pode, pois, dispersar-se em centralidades parciais e móveis (policentralidade), cujas relações concretas determinam-se conjunturalmente. (LEFEBVRE, 1999, p. 90-91)
}

Se o urbano pode ser definido pelas centralidades e estas se definem por seu poder de atração, podemos recolocar a questão deste artigo: que tipo de "atração" exercem os bairros mais "distantes" em Juazeiro? Eles constituem, realmente, "centralidades"? Que "coisas", que "obras" e quais pessoas são atraídas para estes espaços? Ou poderíamos dizer que são, na verdade, empurradas para eles por não serem consideradas dignas do direito aos "espaços centrais"?

De acordo com Milton Santos (2007) não apenas o espaço recebe um "valor", através dos processos sociais de produção, mas também, este valor reverte sobre aqueles que ocupam este espaço. Os lugares da cidade (para moradia, trabalho, lazer, educação etc.) a que um indivíduo tem acesso determinam seu "valor" como cidadão:

Cada homem vale pelo lugar onde está: o seu valor como produtor, consumidor, cidadão depende de sua localização no território [...] Pessoas com as mesmas virtualidades, a mesma formação, até o mesmo salário têm valor diferente segundo o lugar onde vivem: as oportunidades não são as mesmas. (SANTOS, 2007, p.107) 
No caso dos bairros investigados, não é somente o bairro que está marginalizado quanto as questões estruturais. Mas os próprios habitantes que carregam o estigma da pobreza. Por mais que existam moradores com poder financeiro ou instrução de nível superior no Itaberaba, por exemplo, ele não teria o mesmo respaldo "social" que um residente de área nobre em Juazeiro.

Lúcio Kowarick cunhou termo espoliação urbana para analisar as consequências multidimensionais do acesso (ou falta de) a certas áreas urbanas, mais valorizadas. Segundo o autor o conceito enfoca o risco de se sofrer danos ou agressões fora do ambiente laboral, sem que o cidadão disponha de acesso aos recursos para saná-los (KOWARICK apud SOLDANO, 2008, p. 43). A relação entre o local de moradia e a restrição de acesso a estes recursos tem sido um dos grandes temas dos estudos urbanos no Brasil desde a segunda metade do século XX. Áreas precárias e que necessitam de uma intervenção do poder público, são deixadas em planejamento secundário. O conjunto definido por Kowarick (2000) que traduzem a espoliação urbana como "inexistência ou precariedade de serviços de consumo coletivo, as longas horas despendidas nos transportes coletivos até a precariedade de vida nas favelas, cortiços ou casas autoconstruídas em terrenos geralmente clandestinos e destituídos de benfeitorias básicas" (KOWARICK, 2000, p.22) são verificados nos bairros de Itaberaba e João Paulo II, em Juazeiro.

As afirmações acima parecem contraditórias com a própria noção de cidadania, porém, tanto Lefebvre (1999) e Gottdiener (2010) quanto Santos (2007) nos mostraram, se o espaço urbano carrega o potencial do encontro e da criação, carrega também (e ao mesmo tempo) as possibilidades de conflito e destruição. Na verdade, é na relação dialética entre estes dois aspectos que as cidades se constroem, transformam-se e expandem-se. Cabe aos agentes sociais buscar caminhos para se inserir nesse processo de modo a tentar alterar seu entorno de acordo com seus anseios e experiências.

Segundo David Harvey, é preciso ir além da busca pela melhoria de indicadores, pois o direito à cidade não se limita às possibilidades de acesso àquilo que já está constituído/construído, porém, mais do que isso, "[...] é o direito de mudar a cidade mais de acordo com o desejo de nossos corações.” (HARVEY, 2013, p. 36). Este autor, seguindo a perspectiva aberta por Henry Lefebvre (1999), não parte de uma definição fixa do urbano e sim de um objeto que se encontra em processo de feitura, posto que é, simultaneamente, base e alvo de nossas ações (sociais) cotidianas. 
O fenômeno urbano seria o fenômeno social total tão procurado pelos sociólogos? Sim e não. Sim, no sentido em que o urbano caminha para uma totalidade sem jamais atingi-la, em que ele se revela totalizador por essência (a centralidade), sem que essa totalidade se efetue jamais. Sim, no sentido em que nenhum determinismo parcial, nenhum saber parcelar, o esgota; [...] Se o urbano é total, não o é à maneira de uma coisa, enquanto conteúdo (este ou aquele) reunido aqui ou ali, ele o é à maneira do próprio pensamento que persegue indefinidamente sua concentração, que não pode limitar-se a ela nem mantê-la, que reúne sem cessar seus elementos e descobre o que reúne numa concentração outra e nova. A centralidade define o utópico (o que não tem lugar e o procura). O u-tópico define a centralidade. (LEFEBVRE, 1999, p. 154)

Dessa forma, não são apenas as características empíricas da urbanização que permitem analisar a relação dos habitantes com a cidade, mas principalmente, o lugar que os diversos grupos sociais ocupam na dinâmica de apropriação deste espaço (suas diferentes relações com as "centralidades" urbanas), na qual o capital financeiro, a propriedade privada de imóveis e regulamentação dos usos da cidade têm determinado papel preponderante, em detrimento de parcelas da população menos providas de renda (MARICATO, 2013). Os bairros, geralmente, constituem o local de residência e base de amplo convívio social, além de “transmitir" seu valor a seus moradores, como argumentou Milton Santos (2007), acreditamos que são locais privilegiados para se iniciar uma proposta de apropriação mais democrática da cidade pelos seus habitantes.

Assim, foi de interesse do projeto promover debates entre os moradores de dois bairros de Juazeiro (Itaberaba e João Paulo II), acerca das principais dificuldades vividas e sentidas em seu uso cotidiano do espaço e dos serviços urbanos. Como também, as possíveis formas de minimizar situações de espoliação, seja através da ação direta, seja através da cobrança aos poderes públicos.

As metas consistiram em realizar encontros com os atores locais; construir um diagnóstico juntamente com a participação popular; realizar parcerias com instituições sociais dos bairros para acompanhar a manutenção do trabalho; elaborar e distribuir material impresso com informações e contatos que fossem úteis para a população buscar juntos aos órgãos públicos, soluções em relação aos entraves estruturais que acometem a localidade; incentivar por meio de seminários ações concretas que ampliem a apropriação subjetiva do espaço (limpeza urbana, coleta de lixo, melhoria dos espaços de lazer; e por fim, criar ou reativar veículos de comunicação disseminem informações a respeito do tema tratado.

O processo de organização das metas ocorreu em conjunto com os estudantes de Ciências Sociais, que participavam das reuniões destacando como a ação extensionista poderia promover um diálogo entre a comunidade e a academia. A princípio encontramos 
dificuldades no bairro Itaberaba, pelo acesso e pela abordagem aos residentes que não se mostravam interessados em participar da proposta elencada. Porém, a primeira experiência foi crucial para readequar as ações e implantá-las no bairro João Paulo II. Entre elas, procuramos "representantes sociais" (líderes de associações, horta comunitária e comunicadores) que pudessem somar ao grupo, como intermediadores.

\section{Panorama diagnosticado}

As respostas às ações dos dois bairros foram distintas. As problematizações levantadas foram as mesmas no Itaberaba e no João Paulo II, sendo central a questão da precariedade urbana. O trabalho de coleta das informações, partiu inicialmente da análise censitária dos bairros (Censo, IBGE 2010), encontros iniciais com as lideranças para a apresentar o projeto e por fim, a aplicação do questionário com temas selecionados sobre a infraestrutura urbana. Para melhor compreender os resultados encontrados pela equipe do projeto, cabe uma análise comparativa entre ambos os bairros.

\section{Bairro João Paulo II}

Figura 2 - Vista panorâmica do bairro João Paulo II

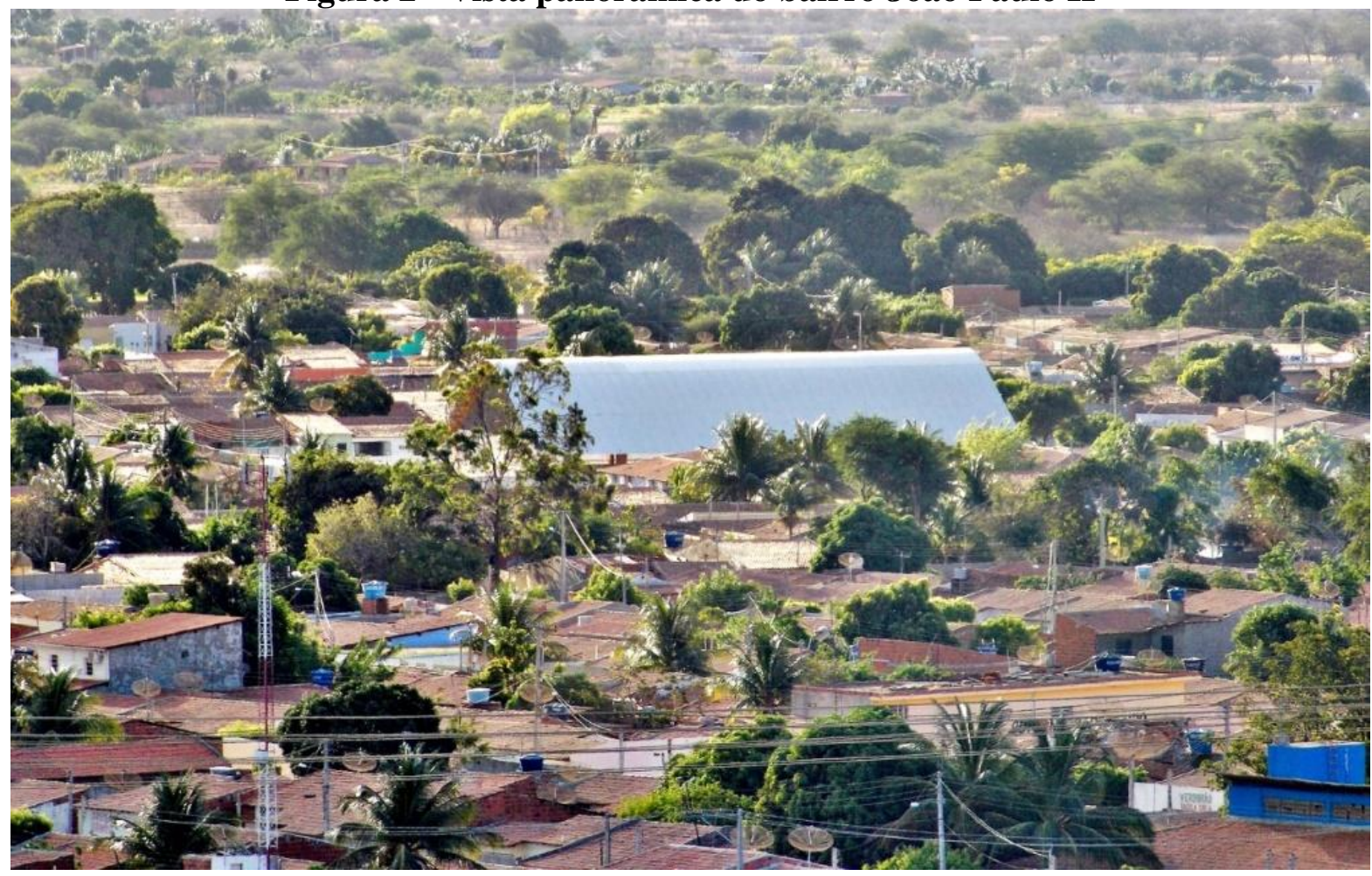

Foto: Harisson Souza, 2014. 
SOUZA, C. H.; DUCCINI, L.

Aspectos de precariedade urbana nos bairros Itaberaba e João Paulo II em Juazeiro (BA)

Tabela 1 - João Paulo II: Perfil sociodemográfico

\begin{tabular}{l|l}
\hline \multicolumn{1}{c|}{ Variável } & \multicolumn{1}{c}{ Dados } \\
\hline População & 19.936 \\
\hline Domicílios & 5.377 \\
\hline Taxa de Migrantes & $45,6 \%$ \\
\hline Renda Média Mensal Domiciliar & $\mathrm{R} \$ 1.090$ \\
\hline $\begin{array}{l}\text { Percentuais de residentes que frequentavam } \\
\text { cursos de educação }\end{array}$ & $\begin{array}{l}\text { Ensino Fundamental (20,5\%); Ensino Médio } \\
(6,1 \%) ; \quad \text { Ensino Superior (1,6\%) Pós- } \\
\text { graduação (-) }\end{array}$ \\
\hline Situação dos Domicílios & $\begin{array}{l}\text { Computador com acesso à Internet (9,2\%); } \\
\text { Televisão (93,5\%); Telefonia (83,2\%). }\end{array}$ \\
\hline Distância para o Centro da Cidade & $\begin{array}{l}\mathbf{1 0} \text { km (marco: Catedral de Nossa Senhora das } \\
\text { Grotas) }\end{array}$ \\
\hline
\end{tabular}

Fonte: IBGE, Censo 2010.

Durante as décadas do século XX a vazão do rio São Francisco era desregulada e as enchentes ocorriam em intervalos temporais relativamente curtos.

O bairro surgiu em 1979-80 através da doação de terrenos para os desabrigados pela grande enchente do São Francisco, ocorrida aquela época. A princípio muitas famílias desistiram de residir nele em decorrência da falta de energia, água e outras condições estruturais precárias (SOUZA, 2014, p.57)

O histórico do bairro é marcado por movimentos de luta por melhorias na qualidade de vida da população. Esse sentimento acabou articulando de forma mais intensa alguns representantes sociais como é o caso das igrejas: Católica e protestante, associação de moradores, grupos da horta comunitária e outros atores que desempenhavam ações fundamentais de reivindicações local. Pela sua grande população, para os parâmetros urbanos de Juazeiro, o bairro é alvo de campanhas de candidatos ao legislativo municipal em anos de eleições.

Um fator que chama atenção é a alta taxa de migração do João Paulo II. De acordo com Souza (2014) o baixo custo ${ }^{1}$ dos terrenos foi decisivo para a ocupação de famílias mais carentes que migraram para o Vale do São Francisco em busca de estudo e melhores oportunidades de emprego.

Durante os trabalhos realizados pela equipe do projeto foi perceptível que o crescimento populacional e imobiliário, oriundos do programa federal de habitação Minha

\footnotetext{
${ }^{1}$ A equipe não encontrou o valor médio dos terrenos do bairro, comparado ao município. Esta informação foi obtida através do relato dos próprios moradores que participaram do projeto.
} 
Casa Minha Vida, contribuiria com o aumento da demanda pelos serviços públicos, como saúde e educação que, já na época, não eram suficientes para atender a população residente.

A pesquisa de campo foi realizada com a aplicação de 50 questionários na área central do bairro, nos novos conjuntos habitacionais e também na associação dos moradores. A finalidade era encontrar, a partir da ótica popular, as principais deficiências estruturais da localidade. Boa parte das informações foram confirmadas pelas hipóteses formuladas através dos resultados do Censo IBGE, em 2010.

Das questões que foram respondidas, alguns recortes foram selecionados para serem expostas neste artigo. Dentre eles, os aspectos mais relevantes da infraestrutura do João Paulo II a partir da tabulação dos questionários.

\begin{tabular}{|c|c|}
\hline Variável & $\begin{array}{c}\text { Maiores percentuais obtidos no } \\
\text { Questionário }\end{array}$ \\
\hline $\begin{array}{l}\text { Qualidade da Água da Rede } \\
\text { Pública }\end{array}$ & $64 \%$ boa \\
\hline Rede de Esgoto Ligada & 58\% dos domicílios dos entrevistados \\
\hline Qualidade do Serviço de Esgoto & $\mathbf{2 8 , 5 \%}$ regular \\
\hline $\begin{array}{l}\text { Existência de Luz elétrica no } \\
\text { domicílio }\end{array}$ & 100\% dos domicílios dos entrevistados \\
\hline Qualidade do serviço de luz & $76 \%$ boa \\
\hline $\begin{array}{l}\text { Se já foi atendido pelo Serviço } \\
\text { Público em alguma reinvindicação }\end{array}$ & $\begin{array}{l}\text { 70\% sim } \\
\text { 30\% não }\end{array}$ \\
\hline $\begin{array}{l}\text { Qualidade de atendimento na } \\
\text { resolução do caso }\end{array}$ & $\begin{array}{l}\mathbf{2 7 \%} \text { resolvido com bom atendimento } \\
\mathbf{2 7 \%} \text { resolvido com péssimo } \\
\text { atendimento }\end{array}$ \\
\hline $\begin{array}{l}\text { Se conhecia o Órgão público } \\
\text { adequado para as devidas } \\
\text { resoluções }\end{array}$ & $\begin{array}{l}\mathbf{5 6 \%} \text { conheciam } \\
\mathbf{4 4 \%} \text { desconheciam }\end{array}$ \\
\hline \multirow{3}{*}{$\begin{array}{c}\text { Destaques da avaliação quanto aos } \\
\text { Serviços públicos e a estrutura do } \\
\text { Bairro }\end{array}$} & Pavimentação $\mathbf{- 4 2 \%}$ péssima \\
\hline & Condições das calçadas - $\mathbf{4 6 \%}$ ruim \\
\hline & Coleta de Lixo $-64 \%$ boa \\
\hline \multirow[b]{2}{*}{ Equipamentos públicos para lazer } & $46 \%$ insuficientes \\
\hline & $\begin{array}{l}\mathbf{3 8 \%} \text { péssimas as condições de } \\
\text { manutenção }\end{array}$ \\
\hline Questionários aplicados & 50 \\
\hline
\end{tabular}

Diante dos números expostos, ficou perceptível que as pessoas estão insatisfeitas com o quadro estrutural do bairro, destacamos os indicadores do esgoto (28,5\% regular) e a pavimentação (42\% péssima). $\mathrm{O}$ aspecto das ruas e avenidas mostraram a deficiência no tratamento do esgoto a falta de pavimentação, em boa parte delas a terra batida e o mau cheiro 
incomodava os moradores. Foram os questionamentos mais apontados pelos participantes como símbolo da precariedade local.

Também foi diagnosticado a necessidade de medidas mais eficazes para melhorar o nível de engajamento social daqueles atores. Alguns encontros com grupos focais foram agendados, porém no decorrer do projeto foi mais eficiente a distribuição de folders impressos com as informações e contatos para cada serviço público, destaca durante a fase de coleta de dados. O grupo contou com o engajamento da Associação de Moradores do João Paulo II e pode alcançar maior campo de atuação em decorrência da parceria.

Os novos conjuntos habitacionais no João Paulo II (que já tinha forte imigração com mais de $45 \%$ dos moradores sendo de outros municípios), tendem a modificar ainda mais a estrutura sociodemográfica do bairro. Cerca de 1.500 novos domicílios foram construídos dentro da área de ponderação que o IBGE delimitou para o bairro. Em um dos condomínios já havia o esboço da implantação de uma associação local, que parecia seguir a mesma tendência de reivindicação em relação a ausência de postos de saúde e novas creches para contemplar a população. Esta era uma preocupação intensa por parte tantos dos novos habitantes, como também dos mais antigos temendo o agravamento da saturação e precarização desses serviços.

Por mais que muitos problemas mencionados no João Paulo II sejam também enfrentados pelo Itaberaba, as respostas encontradas pelo grupo de pesquisa foram diferenciadas.

Comparando com o bairro João Paulo II, o Itaberaba é superado no acesso a educação por parte dos seus moradores, como mostra a tabela 3 nos percentuais de residentes que frequentavam cursos de educação. Também possui domicílios mais precários e uma renda média mais baixa, mesmo tendo menor população que o João Paulo II.

O Itaberaba já tinha alguns moradores na década de 1970-80. Ele possui um importante equipamento para a economia do município que é o Mercado do Produtor - um dos maiores CEASAs (Centrais Estaduais de Abastecimento) do Brasil em movimentação. A comercialização de hortifrutigranjeiros no local atraiu muitos residentes que trabalhavam neste setor. Durante as visitas da equipe era comum encontrar moradores que tinham alguma ligação direta ou indireta com o entreposto comercial. 


\section{- Bairro Itaberaba}

Figura 3 - Visão panorâmica do bairro Itaberaba

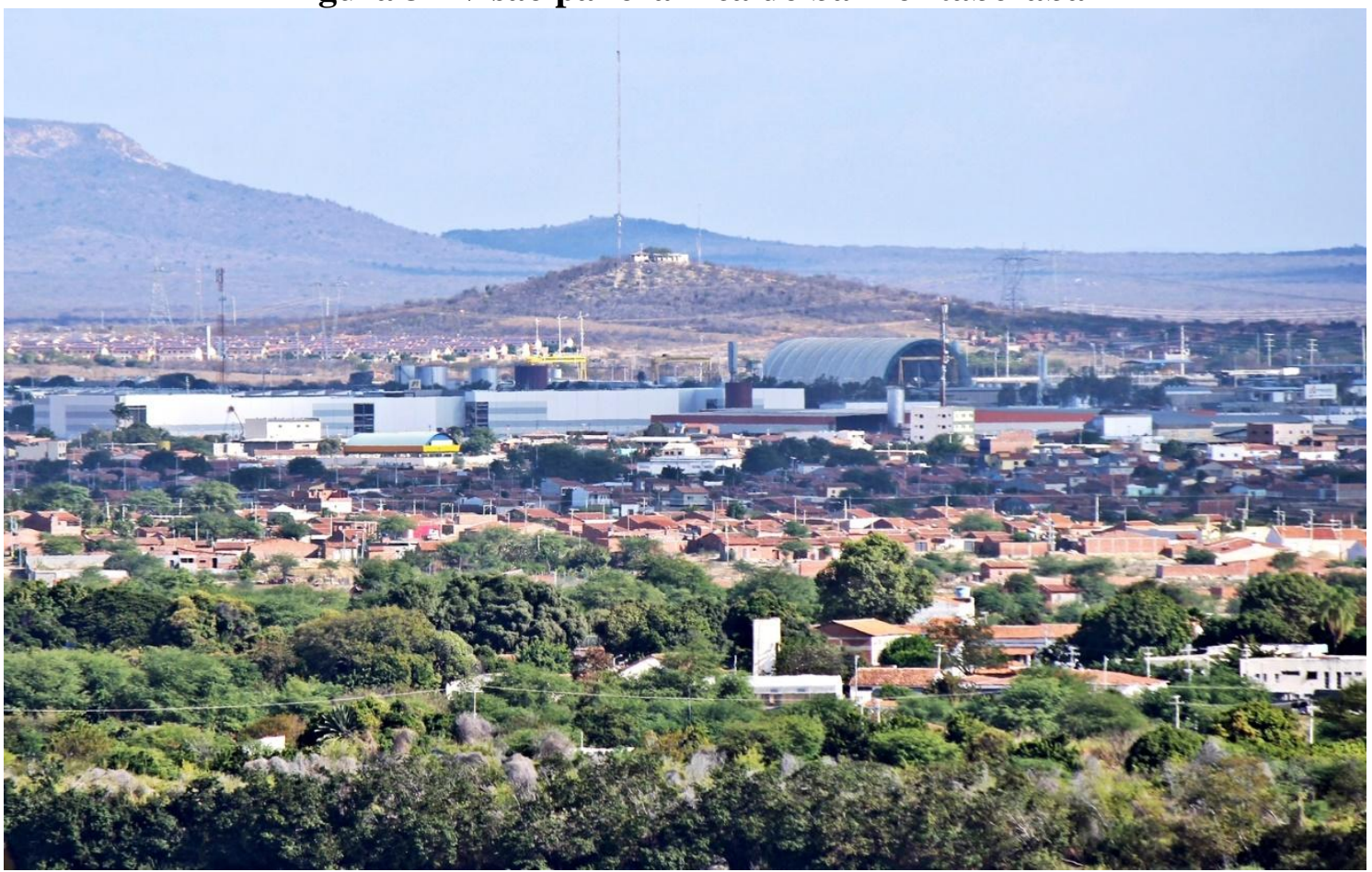

Foto: Harisson Souza, 2015.

Tabela 3 - Itaberaba: Perfil sociodemográfico

\begin{tabular}{l|l}
\hline \multicolumn{1}{c|}{ Variável } & \multicolumn{1}{c}{ Dados } \\
\hline População & 14.494 \\
\hline Domicílios & 4.026 \\
\hline Taxa de Migrantes & $36,9 \%$ \\
\hline Renda Média Mensal Domiciliar & $\mathrm{R} \$ 977$ \\
\hline $\begin{array}{l}\text { Percentuais de residentes que frequentavam } \\
\text { cursos de educação }\end{array}$ & $\begin{array}{l}\text { Ensino Fundamental (18,5\%); Ensino Médio } \\
(4,1 \%) ; \quad \text { Ensino Superior (0,9\%) Pós- } \\
\text { graduação }(0,06 \%)\end{array}$ \\
\hline Situação dos Domicílios & $\begin{array}{l}\text { Computador com acesso à Internet (3,5\%), } \\
\text { Televisão }(94,8 \%) ; \text { Telefonia }(79,8 \%) .\end{array}$ \\
\hline Distância até o Centro da Cidade & $\begin{array}{l}\text { 6 km (marco: Catedral de Nossa Senhora das } \\
\text { Grotas) }\end{array}$ \\
\hline
\end{tabular}

Fonte: IBGE, Censo 2010.

Em 2006 um outro importante centro de compras da bandeira Carrefour - o Atacadão - se instalou nas dependências do bairro que vê sua perspectiva econômica melhorar. Mais recentemente, em 2016, um Shopping Center foi inaugurado por uma das principais empresas nacionais de operacionalização do ramo - Tenco. 
Estas mudanças estruturais no bairro são recentes e na época do nosso projeto não foi possível analisar os impactos do shopping porque ainda não havia iniciado a sua construção. Como todo agente transformador, provavelmente levará um certo tempo para modificar culturalmente e socialmente muitos aspectos da população do bairro.

A questão é que já se nota uma valorização nas áreas adjacentes ao polo comercial que está surgindo no Itaberaba. Baltrusis (2010) tem algumas colocações referentes ao processo pelo qual passa o bairro atualmente.

É o momento em que algum empreendimento de grande porte ou obra estruturante, aporta em determinado local atraindo o interesse imobiliário. Vivencia-se, então, a era urbana dos três "rês" - renovação, revitalização, reurbanização - objetivando reestruturar o espaço das cidades, valorizar áreas degradadas, tornar visíveis e aprazíveis os centros urbanos, e preparar a cidade para a competição mundial. (SOUZA, 2014.p. 41 apud BALTRUSIS, 2010)

Trata-se de um processo cujos efeitos serão perceptíveis com mais ênfase a médio e longo prazo. No momento as duplicações das vias e as melhorias na iluminação de entorno do shopping são as mudanças mais notáveis. Entretanto, ainda persistem a precariedade estrutural nas ruas internas do bairro junto a vulnerabilidade social. (Traga imagens que retratem esta precariedade).

Da tabela 4 destacamos os itens sobre a qualidade das calçadas (41\% ruim) e a inexistência de equipamentos de lazer (86\% afirmaram não existir nas dependências do bairro). Nos encontros com a comunidade e nos trabalhos de coleta, observamos que o Itaberaba tem vias de passeio piores que a média da cidade. As calçadas são desniveladas e inacessíveis a, por exemplo, pessoas com deficiências. O lazer, de fato, era bastante incipiente a demanda local. Não havia praças, nem espaços para prática de caminhadas ao ar livre ou até mesmo ciclismo.

O cenário descrito confirma as análises visuais do grupo a respeito da infraestrutura do Itaberaba. O primeiro contato da equipe do projeto foi em uma associação que não se intitulava como "dos moradores", mas tinha atuação para quem residia por lá. Os encontros contaram com a presença massiva de mulheres e o nome da instituição era Associação de Mães e Amigos do Bairro Itaberaba.

As ações variavam desde a marcação de consultas médicas, até algumas solicitações na prefeitura para melhorar algumas escolas e realizar matrículas. Também haviam convênios com uma empresa de gás para redução dos custos na compra do botijão 
para aqueles associados. Existia uma taxa de 2 reais que era paga pelos membros, não foi mencionada se era mensal ou semanal.

\section{Tabela 4 - Itaberaba: Problemas de infraestrutura na visão dos citadinos}

\begin{tabular}{|c|c|}
\hline Variável & $\begin{array}{c}\text { Maiores percentuais obtidos no } \\
\text { Questionário }\end{array}$ \\
\hline Qualidade da Água da Rede Pública & $\mathbf{4 8 \%}$ boa \\
\hline Rede de Esgoto Ligada & $\mathbf{2 6 \%}$ dos domicílios dos entrevistados \\
\hline Qualidade do Serviço de Esgoto & $63 \%$ boa \\
\hline Existência de Luz elétrica no domicílio & $\mathbf{1 0 0 \%}$ dos domicílios dos entrevistados \\
\hline Qualidade do serviço de luz & $100 \%$ boa \\
\hline $\begin{array}{l}\text { Se já foi atendido pelo Serviço Público em } \\
\text { alguma reinvindicação }\end{array}$ & $\begin{array}{l}87 \% \text { não } \\
13 \% \text { sim }\end{array}$ \\
\hline $\begin{array}{l}\text { Qualidade de atendimento na resolução do } \\
\text { caso }\end{array}$ & $\begin{array}{l}\mathbf{5 0 \%} \text { resolvido com bom atendimento } \\
\mathbf{5 0 \%} \text { resolvido com ruim atendimento }\end{array}$ \\
\hline $\begin{array}{l}\text { Se conhecia o Órgão público adequado para as } \\
\text { devidas resoluções }\end{array}$ & $\begin{array}{l}\mathbf{2 6 \%} \text { conheciam } \\
\mathbf{7 4 \%} \text { desconheciam }\end{array}$ \\
\hline \multirow{3}{*}{$\begin{array}{l}\text { Destaques da avaliação quanto aos Serviços } \\
\text { públicos e a estrutura do Bairro }\end{array}$} & Pavimentação: $\mathbf{5 4 , 5 \%}$ ruim \\
\hline & Condições das calçadas: $\mathbf{4 1 \%}$ ruim \\
\hline & Coleta de Lixo: $\mathbf{5 4 , 5 \%}$ boa \\
\hline \multirow[t]{2}{*}{ Equipamentos públicos para lazer } & $\mathbf{8 6 \%}$ não existem equipamentos de lazer \\
\hline & $\mathbf{9 1 \%}$ não existe manutenção \\
\hline Questionários aplicados & 23 \\
\hline
\end{tabular}

É possível que a valorização dos terrenos no bairro tenha sido modificada após os investimentos da iniciativa privada em construir um shopping center no entorno do Itaberaba. Existe uma expectativa por parte dos moradores em atrair maior atenção do poder público e "repaginar" a infraestrutura local. Atualmente a rodovia que margeia o Itaberaba foi duplicada e iluminada. Também há perspectivas de novos conjuntos habitacionais. A esfera privada estaria "forçando" a esfera pública melhorar as condições estruturais do bairro para então investir.

\section{CONSIDERAÇÕES FINAIS}

As conclusões do comparativo são que, muito embora existam intersecções nas reivindicações do João Paulo II e do Itaberaba, as formas de atuação por parte da população local são diferentes. O nível de escolaridade e o acesso a informação pelos meios midiáticos 
pode ser um dos fatores responsáveis para tal resultado.

As trajetórias históricas são semelhantes quando pautadas na distância, em termos de quilometragem, para o centro da cidade (que ainda concentra os principais serviços) e nas lacunas da infraestrutura - guardadas às suas devidas intensidades em proporção. Ambos receberam uma parcela significativa de imigrantes de baixa renda e alguns investimentos por parte poder público como pavimentação e construção de casas populares em parceria com o governo federal (2010-2015). O valor da terra foi determinado, historicamente, por estar longe do centro tradicional, eis o motivo de abrigar a população de renda mais baixa da cidade, situação similar a ideia apontada por Gottdiener (2010) na discussão teórica.

No setor comercial, o Itaberaba vem se destacando mais do que o João Paulo II, com empreendimentos importantes que arrecadam para o município desde a década passada. Entretanto, ainda falta desenvolver de forma mais adequada os meios de atuação popular e melhorar as condições de acesso por parte dos agentes sociais que lá atuam. A quantidade total de questionários aplicados, 73 nos dois bairros, não é uma amostra representativa por questões estatísticas. Contudo, não deixa de ser um dado interessante ao tema que este trabalho vem abordando.

Existe uma tentativa de regulamentar o Plano Diretor que permanece em sub judice desde a década passada, necessitando passar por discussões com a população. Além disso, é necessário pavimentar ruas e avenidas na periferia urbana e criar espaços de lazer e entretenimento. Entretanto, a demanda é muito alta e não tem suprido as expectativas de muitas pessoas que moram em áreas periféricas.

Como respostas às perguntas elencadas na introdução, por mais que as novas unidades habitacionais do Minha Casa Minha Vida (dentro dos limites do Itaberaba e do João Paulo II) estejam sendo construídas com pavimentação, serviços de água, esgoto e iluminação, a quilometragem desses condomínios até o centro da cidade é considerável (para os parâmetros de Juazeiro) e não contam com um transporte público adequado. As pessoas atraídas para esses espaços distantes, continuam sendo de renda mais baixa e foram realocadas de domicílios em situação de precariedade (casas de taipa, principalmente). Ademais, estes residentes não possuem meios adequados para levar suas demandas ao poder público ou garantir o respeito a seus direitos. Desse modo, podemos dizer que os bairros sofrem com a espoliação urbana, discutida em Kowarick (2000).

Se os empreendimentos recém instalados próximos a esses locais, como o 
shopping center, redes de supermercados e faculdades, irão provocar transformações na rotina desses espaços, as próximas análises trarão novas respostas.

\section{REFERÊNCIAS}

BALTRUSIS, N. (2010). Transformações do modo de morar nas Metrópoles contemporâneas - Novos discursos, velhos problemas. CADERNO CRH, Salvador, v. 23, n. 59, p. 235-253, Maio/Ago. 2010.

CALDEIRA, Teresa. (1997), "Enclaves Fortificados: A Nova Segregação Urbana". Novos Estudos Cebrap, nº 47, pp. 155-176.

IBGE. Instituto Brasileiro de Geografia e Estatística. Cidades@. Disponível em < https://cidades.ibge.gov.br/ > acessado em 15 de julho de 2016.

GOTTDIENER, Mark. A produção social do espaço urbano. São Paulo: Editora da Universidade de São Paulo. 2010

HARVEY, David. A liberdade da cidade. In: MARICATO et. al. Cidades rebeldes [recurso eletrônico]: Passe Livre e as manifestações que tomaram as ruas do Brasil. São Paulo: Boitempo: Carta Maior. 2013

LEFEBVRE, Henri. A revolução urbana. Belo Horizonte: Ed. UFMG. 1999

KOWARICK, Lúcio. Escritos Urbanos. São Paulo: Editora 34, 2000.

MARICATO, Ermínia. É a questão urbana, estúpido! In: MARICATO et. al. Cidades rebeldes [recurso eletrônico]: Passe Livre e as manifestações que tomaram as ruas do Brasil. São Paulo: Boitempo: Carta Maior. 2013.

SANTOS, Milton. O espaço do cidadão. São Paulo: Editora da Universidade de São Paulo. 2007

SOLDANO, Daniela. Vivir en territorios desmembrados. Un estudio sobre la fragmentación socio-espacial y las políticas sociales en el área metropolitana de Buenos Aires (1990-2005). In: ZICCARDI, Alicia. Processos de urbanización de la pobreza y nuevas formas de exclusión social. Bogotá: Siglo Del Hombre Editores, Clacso-Crop. 2008

SOUZA, C.H.S. A relação entre o Crescimento populacional e o Crescimento urbano em Juazeiro - BA. Univasf: 2014. 112 f. Monografia (Graduação em Ciências Sociais Universidade Federal do Vale do São Francisco, Juazeiro, 2014.2) 
Cícero Harisson Souza - Possui Graduação em Ciências Sociais pela Universidade Federal do Vale do São Francisco (UNIVASF) e Mestrado em Geografia pela Universidade Federal de Pernambuco (UFPE). Atualmente é Doutorando em Geografia pelo Programa de PósGraduação da Universidade Federal de Pernambuco (UFPE).

Luciana Duccini - Graduação em Comunicação Social pela Universidade Metodista de São Paulo (UMESP), Mestrado e Doutorado pela Universidade Federal da Bahia (UFBA). Atualmente é Professora pela Universidade Federal do Vale do São Francisco (UNIVASF).

Artigo recebido em: 29 de julho de 2017.

Artigo aceito em: 05 de outubro de 2017. 